\title{
Microalgae Cultivation Using Offshore Membrane Enclosures for Growing Algae (OMEGA)
}

\author{
Patrick Wiley ${ }^{1,2,3}$, Linden Harris ${ }^{1}$, Sigrid Reinsch ${ }^{4}$, Sasha Tozzi ${ }^{5,6}$, Tsegereda Embaye, \\ Kit Clark $^{7}$, Brandi McKuin ${ }^{1,2}$, Zbigniew Kolber ${ }^{5}$, Russel Adams ${ }^{8}$, Hiromi Kagawa ${ }^{7}$, \\ Tra-My Justine Richardson ${ }^{1}$, John Malinowski ${ }^{9}$, Colin Beal ${ }^{10}$, Matthew A. Claxton ${ }^{11}$, \\ Emil Geiger $^{9}$, Jon Rask ${ }^{10}$, J. Elliot Campbell ${ }^{2}$, Jonathan D. Trent ${ }^{* *}$ \\ ${ }^{1}$ Universities Space Research Association, Columbia, USA \\ ${ }^{2}$ School of Engineering, University of California, Merced, USA \\ ${ }^{3}$ PERC Water Corporation, Costa Mesa, USA \\ ${ }^{4}$ NASA Ames Research Center, Moffett Field, USA \\ ${ }^{5}$ Department of Ocean Sciences, University of California, Santa Cruz, USA \\ ${ }^{6}$ Aurora Algae, Inc., Hayward, USA \\ ${ }^{7}$ SETI Institute, Mountain View, USA \\ ${ }^{8}$ Advanced Organic Methods, Penryn, USA \\ ${ }^{9}$ Department of Mechanical Engineering, University of Nevada, Reno, USA \\ ${ }^{10}$ Dynamac Corporation, NASA Ames Research Center, Moffett Field, USA \\ ${ }^{11}$ Department of Chemistry, University of California, Santa Cruz, USA \\ Email: *Jonathan.D.Trent@nasa.gov
}

Received January 23, 2013; revised February 27, 2013; accepted March 19, 2013

\begin{abstract}
OMEGA is a system for cultivating microalgae using wastewater contained in floating photobioreactors (PBRs) deployed in marine environments and thereby eliminating competition with agriculture for water, fertilizer, and land. The offshore placement in protected bays near coastal cities co-locates OMEGA with wastewater outfalls and sources of $\mathrm{CO}_{2}$-rich flue gas on shore. To evaluate the feasibility of OMEGA, microalgae were grown on secondary-treated wastewater supplemented with simulated flue gas $\left(8.5 \% \mathrm{CO}_{2} \mathrm{~V} / \mathrm{V}\right)$ in a 110-liter prototype system tested using a seawater tank. The flow-through system consisted of tubular PBRs made of transparent linear low-density polyethylene, a gas exchange and harvesting column (GEHC), two pumps, and an instrumentation and control (I\&C) system. The PBRs contained regularly spaced swirl vanes to create helical flow and mixing for the circulating culture. About $5 \%$ of the culture volume was continuously diverted through the GEHC to manage dissolved oxygen concentrations, provide supplemental $\mathrm{CO}_{2}$, harvest microalgae from a settling chamber, and add fresh wastewater to replenish nutrients. The I\&C system controlled $\mathrm{CO}_{2}$ injection and recorded dissolved oxygen levels, totalized $\mathrm{CO}_{2}$ flow, temperature, circulation rates, photosynthetic active radiation (PAR), and the photosynthetic efficiency as determined by fast repetition rate fluorometry. In two experimental trials, totaling 23 days in April and May 2012, microalgae productivity averaged $14.1 \pm$ 1.3 grams of dry biomass per square meter of PBR surface area per day $(\mathrm{n}=16)$, supplemental $\mathrm{CO}_{2}$ was converted to biomass with $>50 \%$ efficiency, and $>90 \%$ of the ammonia-nitrogen was recovered from secondary effluent. If OMEGA can be optimized for energy efficiency and scaled up economically, it has the potential to contribute significantly to biofuels production and wastewater treatment.
\end{abstract}

Keywords: Biofuels; Wastewater Treatment; Microalgae; Photobioreactor; $\mathrm{CO}_{2}$ Mass Transfer; Fast Repetition Rate Fluorometry; Instrumentation and Control

\section{Introduction}

Microalgae are currently under consideration as a significant source of sustainable biofuels because of their fast growth rate and ability to produce oil that can be readily transformed into fuel $[1,2]$. These microscopic, single-cell organisms can be cultivated on non-arable land,

"Corresponding author. lessening competition with agriculture and thus giving them an advantage over other biofuel crops [3-5]. On the other hand, microalgae require fertilizer and supplemental carbon dioxide $\left(\mathrm{CO}_{2}\right)$ for optimal growth, which can generate more environmental pollution and greenhouse gas emissions than cultivation of more traditional biofuel feedstocks, such as switchgrass, canola, and corn [6-8]. Several authors have noted that these environmental 
drawbacks can be ameliorated by linking microalgae cultivation to wastewater treatment plants (to provide water and nutrients) and flue gas sources (to provide $\mathrm{CO}_{2}$ ), which also improves the economics and energy return on investment (EROI) $[6,9,10]$. The feasibility of constructing microalgae cultivation facilities close to existing wastewater plants to avoid the prohibitive costs of pumping water long distances will depend on the location [11]. For most metropolitan areas, installing large microalgae ponds or fields of photobioreactors (PBRs) on land would significantly disrupt urban infrastructure. For coastal cities, however, which use offshore wastewater outfalls, a system of floating photobioreactors (PBRs) called Offshore Membrane Enclosures for Growing Algae (OMEGA) may resolve this difficulty [12].

The proposed OMEGA system is designed to grow freshwater microalgae in wastewater contained in flexible, clear, plastic PBRs attached to a floating infrastructure anchored offshore in protected bays [12-14]. The offshore placement allows the system to be in close proximity to wastewater treatment plants and sources of flue gas, eliminating the need to pump these wastes long distances to remote locations where land resources for algae cultivation may be available. By using wastewater for water and nutrients and by not using arable land the OMEGA system avoids competing with agriculture or disrupting urban infrastructure in the vicinity of wastewater treatment plants. On a scale relevant to biofuels, OMEGA will be intrusive in the marine environment, although it is possible that a large flotilla of PBRs may have beneficial effects in coastal areas. The OMEGA system would remove nutrients from the wastewater that is currently discharged into coastal waters and may thereby mitigate "dead-zone" formation. The infrastructure would provide substrate, refugia, and habitat for an extensive community of sessile and associated organisms [15]. It is known that introduced surfaces in the marine environment become colonized and can form "artificial reefs" or act as "fish aggregating devices," which increase local species diversity and expand the food web $[16,17]$. A large-scale deployment of OMEGA systems may also act as floating "turf scrubbers" and function to absorb anthropogenic pollutants, improving coastal water quality [18].

The technical feasibility of the OMEGA concept however, has yet to be evaluated at any scale. Here a prototype, 110-liter OMEGA system was developed and tested in a seawater tank, using freshwater microalgae and secondary-treated wastewater. The details of the system design are described, including the gas exchange and harvesting system as well as the essential monitoring and control instrumentation. This OMEGA prototype maintained viable microalgae cultures, recovered ammonianitrogen $\left(\mathrm{NH}_{3}-\mathrm{N}\right)$ from wastewater, and sustained areal productivities at levels similar to those reported for other cultivation systems. Furthermore, the prototype utilized supplemental $\mathrm{CO}_{2}$ with greater efficiency than other cultivation systems. These results support the proposal that offshore microalgae cultivation, co-located with waste resources, can contribute to the production of biofuels without competing with agriculture $[12,13]$.

\section{Materials and Methods}

\subsection{Seawater Tank and Microalgal Cultures}

Experiments were conducted in an 8800-liter seawater tank at the California Department of Fish and Game, Marine Wildlife Veterinary Care and Research Center in Santa Cruz, CA (Lat: $36^{\circ} 57^{\prime} 13^{\prime \prime}$, Long: $\left.-122^{\circ} 3^{\prime} 56^{\prime \prime}\right)$. The tank was covered at night with a thermal pool blanket to minimize heat loss. A mixed culture of green microalgae used as the system inoculum was dominated by Desmodesmus sp. and grown in 19-liter glass carboys containing either BG11 medium (ATCC) or secondary wastewater effluent. The carboys were aerated continuously with a regenerative blower (Model VFC084P-5T, Fuji Blowers, Saddle Brook, NJ) and periodically injected with pure $\mathrm{CO}_{2}$ to lower the culture $\mathrm{pH}$ and provide a source of carbon.

\subsection{PBR System}

Tubular PBRs contained swirl vanes to enhance mixing by creating a spiral flow and were connected by pipes and fittings to each other and to the rest of the circulation system (Figure 1). The PBRs were constructed by welding sheets of 15-mil clear linear low-density polyethylene (LLDPE) into tubes (I.D. $11.4 \mathrm{~cm} \times 3 \mathrm{~m}$ long) using an AIE double impulse foot heat sealer (Industry, CA). The swirl vanes, improvised from polyethylene grain augers (Lundell Plastics Corporation, Odebolt, IA) were fixed inside a transparent schedule 40 polyvinyl chloride (PVC) collar (O.D. $11.4 \mathrm{~cm} \times 5.1 \mathrm{~cm}$ long) with a steel pin. The sharp edges of the PVC collar were removed with a bench grinder to prevent damaging the LLDPE. The swirl vanes

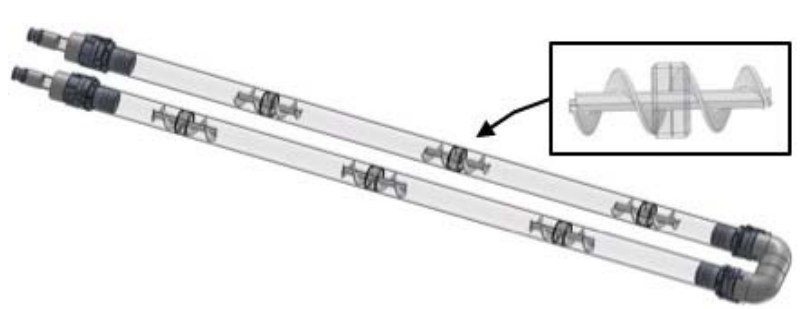

Figure 1. OMEGA photobioreactor (PBR) tubes with swirl vanes. PBRs were made of flexible, clear LLDPE connected with cam-lock fittings to a U-shaped PVC manifold. The six swirl vanes (see insert enlargement) directed the flow into a helical path to improve mixing and light exposure of the microalgae. 
were spaced $0.9 \mathrm{~m}$ apart and held in place using cable ties wrapped around the collar on the outside of the PBRs.

The ends of the PBR tubes were attached to cam-lock fittings (Model 400D, Banjo Corporation, Crawfordsville, IN) and connected in series by a U-shaped manifold constructed of two schedule 40 PVC $90^{\circ}$ elbows $(10.2 \mathrm{~cm})$. The 10.2-cm cam-lock fittings on the PBR inlet and outlet were reduced to $5.1 \mathrm{~cm}$ to accommodate the transparent flexible PVC tubing that was connected to the suction and discharge side of a centrifugal pump (Model 1MC1D5D0, ITT-Goulds, Seneca Falls, NY). The speed of the centrifugal pump was adjusted using a 1-HP GS-2 variable frequency drive (Automation Direct, Cumming, GA). A sensor manifold located before the pump inlet housed a paddlewheel flow meter (Model 2537, Georg Fischer LLC, Tustin, CA), pH probe (Model 2750, Georg Fischer LLC, Tustin, CA), and dissolved oxygen (DO) sensor (Sensorex, Garden Grove, CA) and provided connection to the gas exchange and harvesting column (GEHC) (Figure 2).

\subsection{Gas Exchange and Harvesting Column (GEHC)}

The GEHC shown in Figure 3 was designed to: 1) manage concentrations of DO using an oxygen stripping device (OSD) based on a design by Barnhart [19]; 2) supply $\mathrm{CO}_{2}$ to the microalgae culture and control $\mathrm{pH}$; and 3) provide a settling chamber to collect aggregating microalgae for harvesting. Approximately 5\% of the total system volume was diverted to the GEHC per minute, using a 12 VDC SHUR-FLO diaphragm pump (Model 2088-343135, SHUR-FLO, Costa Mesa, CA). The pumping rate into the GEHC was adjusted by changing the voltage setting on the variable DC power supply (Model HY3005D, Mastec Power Supply, San Jose, CA).

The culture from the PBR entered the GEHC through the OSD section and cascaded over five stacked PVC plates $\left(20 \mathrm{~cm}^{2}\right.$ each) housed in a pipe (schedule 40 PVC: $15.2 \mathrm{~cm}$ diameter $\times 0.3 \mathrm{~m}$ ) attached to the top of the GEHC with a rubber coupling (model 1056-63, Fernco Inc., Davidson, MI). After the OSD, the culture entered the gas-injection pipe (schedule 40 clear PVC 7.6-cm diameter $\times 2.13 \mathrm{~m}$ ), containing a $\mathrm{CO}_{2}$ diffuser made from soaker hose $\left(22 \mathrm{~cm}^{2}\right)$ located $1.8 \mathrm{~m}$ from the top of the column. The compressed $\mathrm{CO}_{2}$ source was a mixture of $8.5 \% \mathrm{CO}_{2}$ in air $(\mathrm{V} / \mathrm{V})$ to simulate the concentration of $\mathrm{CO}_{2}$ in typical flue gas [20]. The $\mathrm{CO}_{2}$ input was regulated by a $\mathrm{pH} /$ temperature sensor (GF Signet $2750 \mathrm{pH}$ sensor electronics, Georg Fischer LLC, Tustin, CA).

After the gas-injection section, the culture enters the settling chamber, which consisted of a section of clear pipe (schedule 40 PVC $15.2 \mathrm{~cm}$ diameter $\times 0.91 \mathrm{~m}$ ) with a ball valve $(1.3 \mathrm{~cm})$ drain at the bottom. The culture entered from the gas-injection pipe, which protruded 0.3 $\mathrm{m}$ into the settling chamber, and was capped to direct the outflow to the sides and prevent resuspending biomass collected at the bottom of the chamber. The culture returned to the PBRs from the settling chamber through a pipe (schedule 80 PVC $1.3 \mathrm{~cm}$ diameter) with a flow meter (model F-40377LN-8, Blue-White Industries LTD, Huntington Beach, CA) and a pneumatic pinch valve (1.3 cm VMP Series, AKO Armaturen \& Separations GmbH, Germany). The pinch valve maintained a constant liquid height in the GEHC, using a feedback signal generated by a pressure transducer (model PTD25-10-0015H, Automation Direct, Cumming, GA) in the settling chamber.

\subsection{Instrumentation and Control}

A custom instrumentation and control (I\&C) system was constructed for process automation and data logging (Figure 4). The $\mathrm{pH}$ and temperature sensors in the PBR and GEHC were connected to a GF Signet model 8900 multi-parameter transmitter (Georg Fischer LLC, Tustin, CA). Output signals from the transmitter, GEHC pressure transducer, flow meter, and photosynthetically active radiation (PAR) sensor were attached to inputs of a DL06 programmable logic controller (PLC) (Automation Direct, Cumming, GA). The PLC transferred data to a humanmachine interface (HMI) created using LookoutDirect software (Automation Direct, Cumming, GA) that displayed real-time data and allowed operators to specify

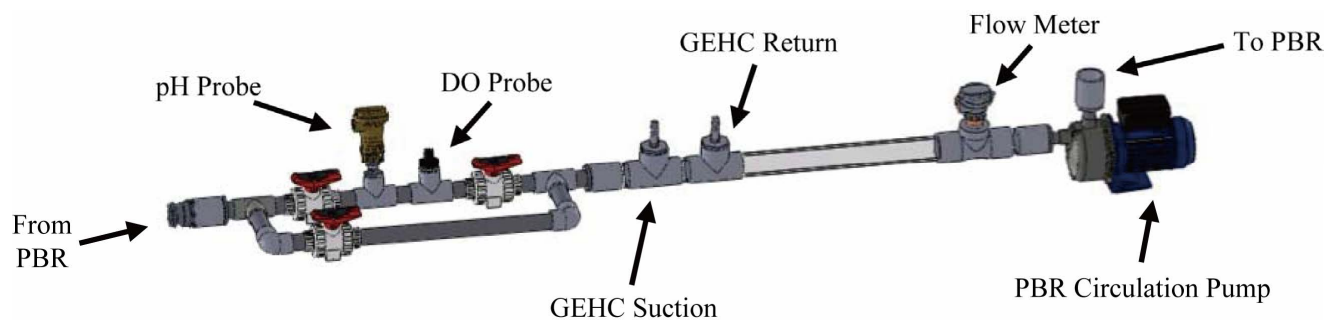

Figure 2. Inline sensors for $\mathrm{pH}$, temperature, DO, and flow rate. The culture was pumped from the PBR past the sensors. Part of the circulating flow was diverted to the GEHC (see Figure 3) at the GEHC suction fitting by a positive displacement pump (not shown) and returned to the PBR flow at the GEHC return. The valved bypass was used to isolate the sensors for cleaning and maintenance without disrupting the overall circulation. 


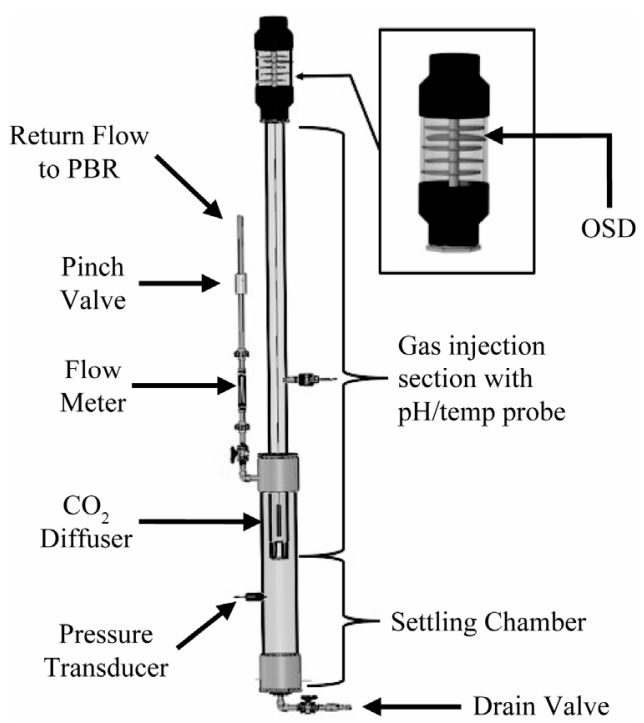

Figure 3. Gas exchange and harvesting column (GEHC) controls $\mathrm{pH}$, removes settled microalgae and provides a location for wastewater addition into the PBR system. An oxygen stripping device (OSD, top) designed to remove excessive concentrations of photosynthetically generated dissolved oxygen was built into the GEHC. $\mathrm{CO}_{2}$ is added by gas bubbles injected with the diffuser at a rate controlled by pH. Biomass collected in the settling chamber is removed, whereas suspended microalgae are returned to the PBR (return flow pipe, left). The pressure transducer controls a pinch valve position to maintain a consistent liquid level in the GEHC. The volume of the GEHC was periodically harvested from the drain valve at the bottom and replaced with wastewater to replenish nutrients in the PBRs.

desired setpoints for the GEHC $\mathrm{pH}$ and liquid level. Feedback control loops generated PLC output signals based on the difference between the actual value and the desired setpoint entered into the HMI. When the $\mathrm{pH}$ in the GEHC exceeded the setpoint, the PLC output signal adjusted $\mathrm{CO}_{2}$ injection rates through an Aalborg massflow controller (MFC) (Aalborg, Orangeberg, NY). Similarly, a current/pressure (I/P) transducer (Model IP610060-D, OMEGA Engineering Inc. Stamford, CT), regulated by the PLC output signal, varied the pinch valve position as needed to maintain the desired liquid level in the GEHC. The objective of both control loops was to minimize the difference between the actual value and the desired set point. DO was measured using a Sensorex DO probe (Sensorex, Garden Grove, CA) and data were recorded using a Craig Ocean Systems (Ben Lomond, CA) data logger. The physiological condition of the microalgae was monitored continuously using a fast repetition rate fluorometer (FRRF) set up for flow-through operation.

\section{5. $\mathrm{CO}_{2}$ Mass Transfer}

The $\mathrm{CO}_{2}$ mass transfer efficiency for the GEHC was

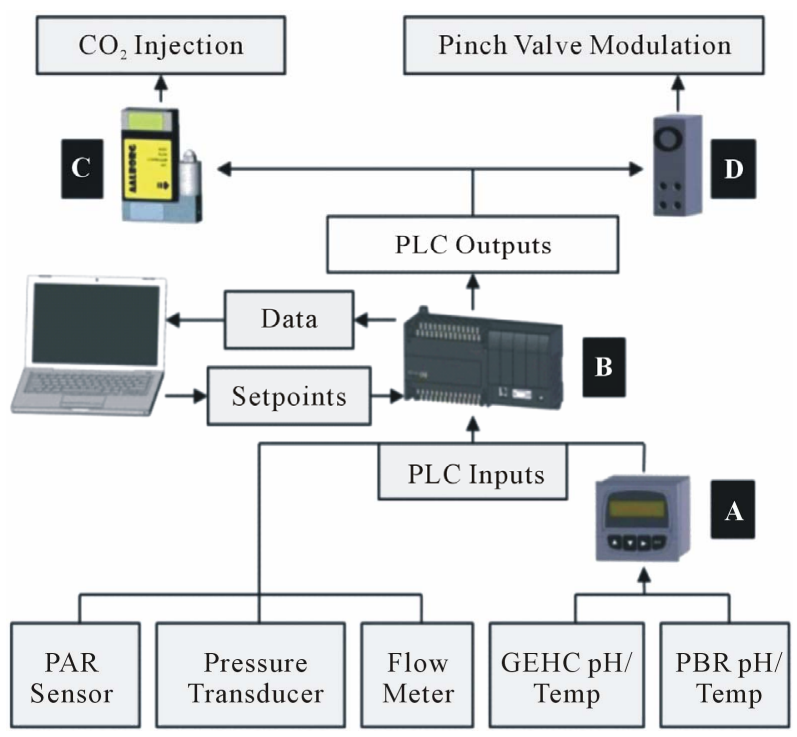

Figure 4. Components of the I\&C system. Inputs from the sensors were routed through a multi-parameter transmitter (A) or directly into a PLC (B) were transferred to a computer database. Setpoint values established using an HMI modulated PLC outputs that controlled a mass flow controller for $\mathrm{CO}_{2}$ injection (C) and an $\mathrm{I} / \mathrm{P}$ transducer (D) to regulate pinch valve positioning.

calculated based on the column height and the gas flow rate required to sustain a target microalgae productivity of $20 \mathrm{~g} \cdot \mathrm{m}^{-2} \cdot \mathrm{day}^{-1}$, in line with the average productivity cited by Putt et al. [21]. Several authors have noted that microalgae biomass is approximately $50 \%$ carbon [2224], a value corroborated by elemental analysis of the algae grown in the OMEGA system (data not shown). These values, together with a $2 \times$ over design factor, were used in Equation (1) to estimate a peak gas injection rate of $0.5 \mathrm{lpm}$ into the GEHC.

$$
\mathrm{Q}_{\text {Gas }}=\frac{\mathrm{P}_{\text {Algae }} \cdot \mathrm{f}_{\text {Carbon }} \cdot \mathrm{A}_{\mathrm{PBR}} \cdot \mathrm{RT}}{\mathrm{D}_{\text {Solar }} \cdot 60 \cdot \mathrm{M}_{\mathrm{Car}} \cdot \mathrm{pCO}_{2}}
$$

The $\mathrm{CO}_{2}$ mass transfer efficiency was quantified for six different GEHC water column levels $(0.3 \mathrm{~m}, 0.6 \mathrm{~m}$, $0.9 \mathrm{~m}, 1.8 \mathrm{~m}, 2.1 \mathrm{~m}$ or $2.7 \mathrm{~m}$ ) using a transparent PVC test column $(3 \mathrm{~m} \times 7.6 \mathrm{~cm})$. A diffuser (described above), used to inject $\mathrm{CO}_{2}(8.5 \%$ in air, $\mathrm{V} / \mathrm{V})$ into solution, was lowered to the bottom of the test column. The $0.5-\mathrm{lpm}$ gas injection rate (from Equation (1)) was controlled using a precision rotometer (Model WU-03218-52, Cole Palmer, Vernon Hills, IL) calibrated with an Agilent ADM1000 Flowmeter (Agilent Technologies Inc., Wilmington, DE). Tap water contained in a plastic barrel was weighed using an Ohaus Defender scale (Ohaus Corporation, Pine Brook, NJ) and the $\mathrm{pH}$ was adjusted to $>11.00$ with a known mass of $\mathrm{NaOH}$. The mass of water corresponding to the desired liquid height was removed from the barrel and added to the test column. The mass of $\mathrm{CO}_{2}$ dissolved 
into solution was determined by measuring the $\mathrm{pH}$ change in the water column using the stoichiometry of the acid-base reaction relationship between the $\mathrm{NaOH}$ and $\mathrm{H}_{2} \mathrm{CO}_{3}^{*}$ described in Equations (2) and (3).

$$
\begin{gathered}
\mathrm{H}_{2} \mathrm{O}+\mathrm{CO}_{2} \leftrightarrow \mathrm{H}_{2} \mathrm{CO}_{3}^{*} \\
\mathrm{H}_{2} \mathrm{CO}_{3}^{*}+2 \mathrm{NaOH} \leftrightarrow \mathrm{Na}_{2} \mathrm{CO}_{3}
\end{gathered}
$$

The $\mathrm{CO}_{2}$ uptake efficiency is the amount of $\mathrm{CO}_{2} \mathrm{ab}-$ sorbed in the GEHC column divided by the amount supplied. The amount of $\mathrm{CO}_{2}$ absorbed was determined indirectly by measuring $\mathrm{pH}$ changes in the water column. The total moles of $\mathrm{CO}_{2}$ injected into the test column was determined using Equation (4), which allowed the calculation of the mass transfer efficiency with Equation (5). For this experiment, the mass transfer efficiency was calculated based on the amount of $\mathrm{CO}_{2}$ required to change the $\mathrm{pH}$ of the solution from 10 to 9,9 to 8,8 to 7 and below 7 .

$$
\begin{aligned}
\mathrm{M}_{\mathrm{CO}_{2}} & =\frac{\mathrm{Q} \cdot \mathrm{t} \cdot \mathrm{pCO}_{2}}{\mathrm{RT}} \\
\mathrm{CO}_{2 \mathrm{Eff}} & =\frac{\mathrm{M}_{\mathrm{NaOH}}}{2 \mathrm{M}_{\mathrm{CO}_{2}}} \cdot 100
\end{aligned}
$$

A comparison of the $\mathrm{CO}_{2}$ mass transfer rate in the GEHC and carbon consumption rate of microalgae in the PBR gave a "detention time ratio" that estimates the amount of time the culture can remain in the PBR before carbon replenishment is needed. The overall mass transfer coefficient $\left(\mathrm{K}_{\mathrm{L}} \mathrm{a}\right)$ and subsequent $\mathrm{CO}_{2}$ mass transfer rate in the GEHC were calculated from the titraion data using Equations (6) and (7), whereas the carbon uptake rate in the PBR was approximated with Equation (8).

$$
\begin{gathered}
\mathrm{K}_{\mathrm{L}} \mathrm{a}=\ln \left(\frac{\mathrm{C}^{*}-\mathrm{C}_{2}}{\mathrm{C}^{*}-\mathrm{C}_{1}}\right) /\left(\mathrm{t}_{2}-\mathrm{t}_{2}\right) \\
\frac{\mathrm{dc}}{\mathrm{dt}}=\mathrm{K}_{\mathrm{L}} \mathrm{a}\left(\mathrm{C}^{*}-\mathrm{C}\right) \\
\mathrm{C}_{\text {Uptake }}=\frac{\mathrm{P}_{\text {Algae }} \cdot \mathrm{f}_{\text {Carbon }} \cdot \mathrm{A}_{\mathrm{PBR}}}{\mathrm{D}_{\text {Solar }} \cdot 60 \cdot \mathrm{M}_{\text {Car }} \cdot \mathrm{PBR}_{\mathrm{Vol}}}
\end{gathered}
$$

Results from Equations (7) and (8) were used to calculate the detention time ratio between the GEHC and the PBR with Equation (9).

$$
\mathrm{DTR}=\frac{\mathrm{GEHC}_{\mathrm{Xfer} \mathrm{Rate}}}{\mathrm{C}_{\text {Uptake }}}
$$

\subsection{System Inoculation, Sampling Protocol, and Harvesting Procedures}

Final plant effluent (FPE) was collected from the Santa Cruz wastewater treatment facility mixed with inoculum in a plastic barrel, and weighed with an Ohaus Defender scale. The contents of the barrel were transferred into the GEHC using a submersible pump. As the liquid level in the GEHC approached the setpoint, the I\&C system opened the pinch valve and diverted liquid into the PBR. The volume required to fill the entire system $(\sim 110 \mathrm{~L})$ was determined by weight.

The optical density $\left(\mathrm{OD}_{750}\right), \mathrm{NH}_{3}-\mathrm{N}$ (Hach method 10031), $\mathrm{NO}_{3}-\mathrm{N}$ (Hach method 8039), and total suspended solids (TSS) concentration (method 2540D) [25] were measured on samples collected daily from a port located on the discharge side of the PBR circulation pump. Differences in the $\mathrm{OD}_{750}$ before and after physically shaking the PBR to resuspend settled biomass were used to determine the percent sedimentation within the PBR using Equation (10).

$$
\mathrm{SED}_{\%}=\frac{\mathrm{OD}_{750_{\text {After }}}-\mathrm{OD}_{750_{\text {Before }}}}{\mathrm{OD}_{750_{\text {After }}}} \cdot 100
$$

The GEHC was drained into a barrel and refilled with fresh FPE when the ammonia concentration approached zero. The barrel was weighed to determine volume (assuming a density of $1 \mathrm{~kg} \cdot \mathrm{l}^{-1}$ ) removed from the GEHC and samples were collected for TSS analysis. The volume of water remaining in the PBR was determined by subtracting the harvest volume from the total system volume. This enabled calculation of the total biomass produced between harvest periods, the biomass concentration factor in the GEHC, and areal productivity (Equations (11)-(13)).

$$
\begin{gathered}
\mathrm{A}_{\text {Growth }}=\mathrm{TSS}_{\mathrm{GEHC}} \cdot \mathrm{H}_{\mathrm{Vol}}+\mathrm{TSS}_{\mathrm{PBR}} \cdot \mathrm{PBR}_{\mathrm{Vol}}-\mathrm{I}_{\text {Mass }} \\
\mathrm{HCF}=\frac{\mathrm{TSS}_{\mathrm{GEHC}}}{\mathrm{TSS}_{\mathrm{PBR}}} \\
\mathrm{P}_{\text {Algae }}=\frac{\mathrm{A}_{\text {Growth }}}{\mathrm{A}_{\mathrm{PBR}} \cdot \mathrm{D}_{\text {Harvest }}}
\end{gathered}
$$

The result from Equation (11) and the totalized volume of gas injected into the GEHC recorded by the I\&C system were used to calculate the $\mathrm{CO}_{2}$-to-biomass conversion efficiency with Equation (14).

$$
\mathrm{CO}_{2_{\text {Conv }}}=\frac{\mathrm{A}_{\text {Growth }} \cdot \mathrm{f}_{\mathrm{Car}}}{\left(\frac{\mathrm{V}_{\mathrm{Gas}} \cdot \mathrm{pCO}}{\mathrm{RT}} \cdot \frac{12 \mathrm{~g} \mathrm{C}}{\mathrm{molCO}_{2}}\right)} \cdot 100
$$

\section{Results and Discussion}

\subsection{System Design and Performance}

A 110-liter prototype OMEGA system was constructed with two tubular PBRs floating in a seawater tank, connected to an external GEHC and an instrumentation and control system (Figure 5). The system components 
(PBRs, GEHC, and I\&C) are described in the Materials and Methods. The PBRs, made of inexpensive plastic (LLDPE), were tested for their ability to support photosynthesis. The GEHC served to control DO, provide $\mathrm{CO}_{2}$, and remove and harvest microalgal biomass. The $\mathrm{I} \& \mathrm{C}$ system monitored or controlled $\mathrm{pH}$, temperature, flow rate, and DO concentrations, recording sensor outputs every three minutes.

Temperature and $\mathrm{pH}$ were measured both near the outlet of the PBR in the sensor manifold (Figures 2 \& 5) and in the GEHC (Figure 3). The two monitoring sites provided comparative data, and the GEHC $\mathrm{pH}$ sensor served to control $\mathrm{CO}_{2}$ injection rates, using a setpoint of $\mathrm{pH}$ 7.60. The I\&C system also included measurements of photosynthetically active radiation (PAR) and the effect of light on cultures using FRRF, a rapid, nondestructive, technique that detects variable chlorophyll fluorescence in real time [26]. A decrease in the ratio of variable fluorescence to maximum fluorescence $\left(\mathrm{F}_{\mathrm{V}} / \mathrm{F}_{\mathrm{M}}\right)$ indicates a decreased quantum yield resulting from damage to photosystem II and is used as an index for photoinhibition [27]. Reported $\mathrm{F}_{\mathrm{V}} / \mathrm{F}_{\mathrm{M}}$ ratios in cultures exposed to high irradiance indicated up to $90 \%$ photoinhibition [27,28].

To limit sedimentation of microalgae in the PBRs, cultures were circulated at velocities ranging from 14 to $21 \mathrm{~cm} \cdot \mathrm{sec}^{-1}$, flow rates that reportedly prevent sedimentation in open ponds [29]. Microalgae suspension and mixing were enhanced by swirl vanes, which imparted a helical flow pattern. With the combination of flow rates and swirl vanes, microalgae settling in the PBRs never exceeded $14 \%$ of the total biomass. The swirl vanes also increased turbulence, which is known to improve nutrient exchange rates and light exposure in PBR cultures [30]. In cultures grown in laminar flow systems photoinhibition and light limitations are observed, both of which suppress productivity [28-30]. While swirl vanes may have improved suspension and light availability and hence productivity, two difficulties noted with the swirl vanes tested were 1) increase biofouling on the walls of the PBR in their vicinity and 2) increased drag, which increased pumping energy.

To assess the performance of the prototype OMEGA system, two consecutive experiments were conducted in April and May 2012. Experiment 1 lasted 13.5 days and experiment 2 lasted 8.6 days. In both experiments 1 and 2 , the comparisons of hourly mean DO vs. PAR and DO vs. Fv/Fm are shown in Figure 6. The increase in photosynthetically generated DO correlates well with PAR from sunrise (06:00) to late afternoon (16:00), although

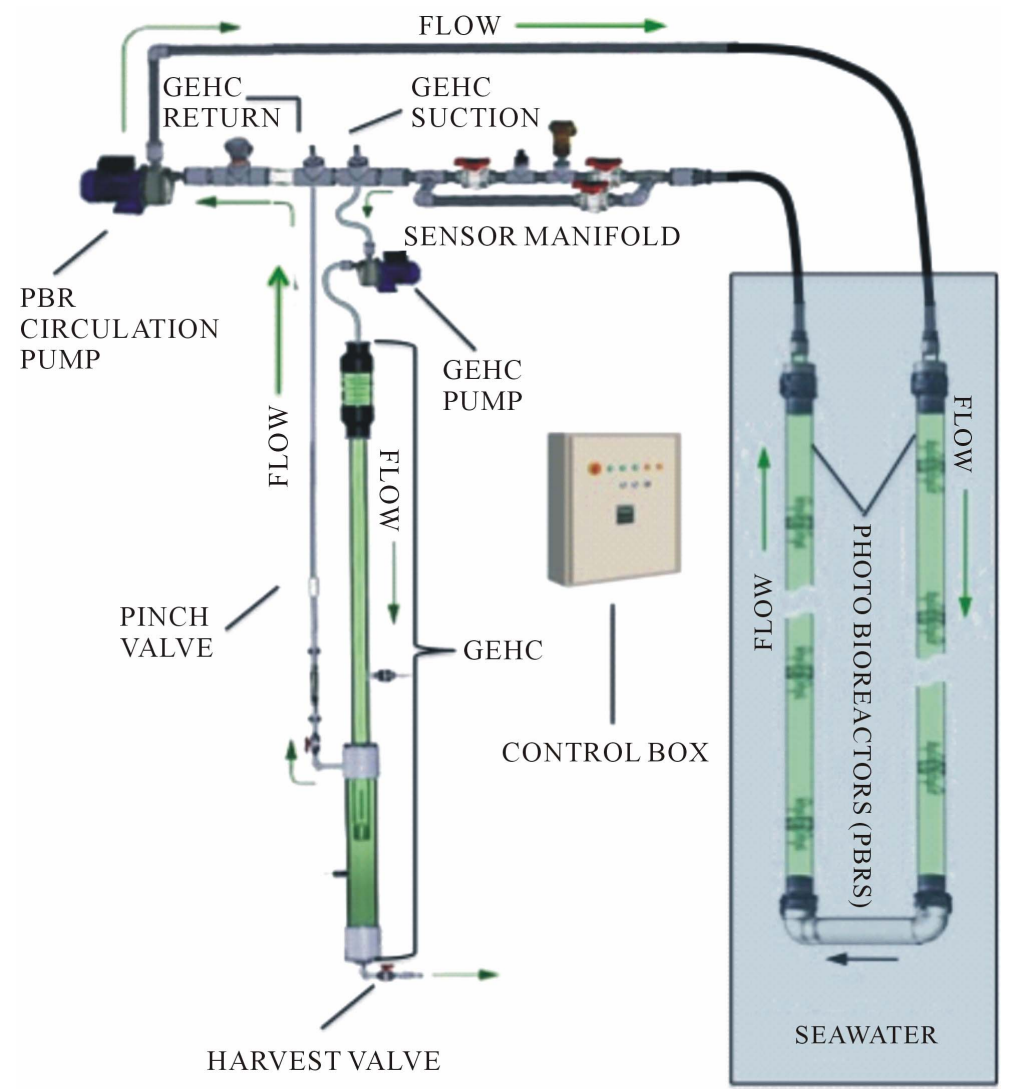

Figure 5. Component and flow diagram of the OMEGA system showing the circulation through the PBRs, sensor manifold, and side loop for the GEHC. 


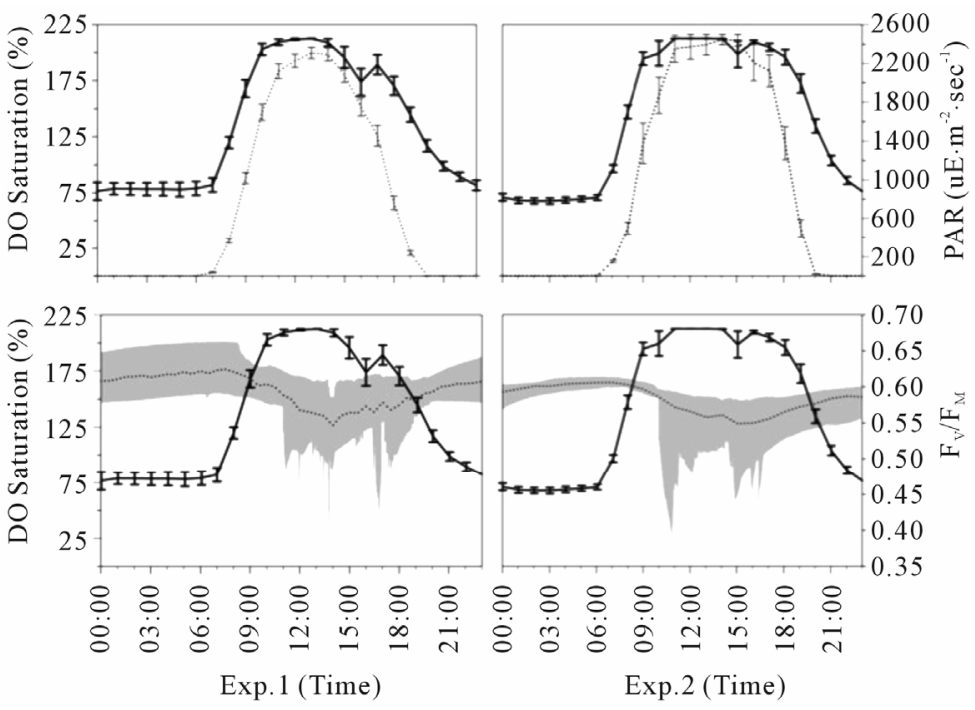

Figure 6. DO concentration, PAR and $F_{V} / F_{M}$ values for Experiment 1 (left) and Experiment 2 (right). (Top) Mean hourly ( \pm SE) concentration photosynthetically generated DO (solid line) increases and decreases as a function of PAR (dotted line). (Bottom) The mean hourly $F_{V} / F_{M}$ ratio (dotted line) overlaying the range of data points (shaded area) measured by $F R R F$ indicates that the culture has maintained high photoconversion efficiency. The slight suppression of the $F_{V} / F_{M}$ ratio during mid-day is a result of photoinhibition caused by PAR intensity and elevated concentrations of DO (solid line).

the DO curve is artificially flattened at peak solar irradiance $(\sim 12: 00)$ because the DO values exceeded the upper threshold for the oxygen sensors (212\% saturation) (Figure 6, DO saturation). After 16:00, the decline in DO was due to a combination of decreased photosynthesis, respiration, and DO removal by the OSD in the GEHC (see Materials and Methods: GEHC). The relative contribution of these different factors was not determined.

At peak DO production and peak irradiance, there was a slight photoinhibition indicated by $\mathrm{F}_{\mathrm{V}} / \mathrm{F}_{\mathrm{M}}$ measurements, which dipped to 0.49 in experiment 1 and 0.54 in Experiment 2 (Figure 6, bottom). Rubio and co-workers [31] noted that in long tubular PBRs DO buildup at high irradiance caused photoinhibition and they identified this as one of the greatest constraints on the scale-up of PBRs. The solution for the OMEGA system is to adjust the ratios of residence time in the PBR to the transfer frequency to the GEHC, which depends on PBR length, the number of GEHCs, and the flow rate. In the OMEGA system the tested residence time of the culture in the PBRs was $20 \mathrm{~min}$, based on a PBR length of $3.1 \mathrm{~m}$, a $4.5 \%$ transfer to the GEHC, and a PBR flow rate of 86 $130 \mathrm{lpm}$. In the future, DO as it relates to photoinhibition can be managed for PBRs of a given length using realtime FRRF and DO data in the control logic algorithm to modify GEHC input and flow rates. The size and configuration of the OSD can also be modified to increase the exchange of DO. In addition to DO management, the GEHC was where $\mathrm{CO}_{2}$ was injected into the culture, both as a source of inorganic carbon for microalgae growth and to control the culture $\mathrm{pH}$. Both carbon availability and $\mathrm{pH}$ control are dependent on efficient $\mathrm{CO}_{2}$ delivery, and both are critical to the productivity and economics of large-scale microalgae cultivation [23,32-35]. Beal et al. $[36,37]$ have shown that commercial $\mathrm{CO}_{2}$ supply is one of the biggest contributors to overall energy use and cost of microalgal biofuel production.

Traditionally $\mathrm{CO}_{2}$ delivery systems, using sparging tubes bubbling into shallow cultures, resulted in $80 \%-90 \%$ losses of $\mathrm{CO}_{2}$ to the atmosphere [21,38]. Diffusion methods, using silicon membranes or hollow fibers reduce $\mathrm{CO}_{2}$ loss to the atmosphere but are cost prohibitive and prone to biofouling $[21,33,39,40]$. Bubble columns, like the GEHC, are simple, low cost, and capable of reducing $\mathrm{CO}_{2}$ losses to less than $20 \%[21,38]$.

\subsection{GEHC Mass Transfer Efficiency and Recycle Rate}

The $\mathrm{CO}_{2}$ mass transfer efficiency in a gas exchange column is influenced by the $\mathrm{pH}$ of the receiving liquid, by the height of the liquid column, which determines bubble contact time, by the size of the bubbles, which determines contact area, and by the $\mathrm{CO}_{2}$ content of the gas bubbles. Experiments with the GEHC indicated that higher $\mathrm{pH}$ and a taller column increased $\mathrm{CO}_{2}$ mass transfer efficiency (Figure 7). In the OMEGA system tested here, however, site restrictions limited the gassing portion of the GEHC to 1.8 meters, which gave a mass transfer efficiency of approximately $50 \%$ for the operating $\mathrm{pH}$ range in the GEHC of between $\mathrm{pH} 7.0$ and 8.25. The overall volumetric mass transfer coefficient $\left(\mathrm{K}_{\mathrm{L}} \mathrm{a}\right)$ 
was $0.21 \mathrm{~min}^{-1}(\mathrm{SE} 0.01, \mathrm{n}=3)$, and the mass transfer rate of $\mathrm{CO}_{2}$ was $1.69 \times 10^{-4} \mathrm{~mol} \cdot 1-\mathrm{min}^{-1}\left(\mathrm{SE} 1.03 \times 10^{-5}\right.$, $\mathrm{n}=3$ ).

Assuming an areal productivity of $20 \mathrm{~g} \cdot \mathrm{m}^{-2} \cdot \mathrm{day}^{-1}$, the carbon consumption rate in the PBR was calculated to be $8.72 \times 10^{-6} \mathrm{~mol} \cdot 1-\mathrm{min}^{-1}$. Balancing the mass transfer rate in the GEHC with the carbon consumed by microalgae would require one minute in the GEHC for every 20 minutes in the PBR. Therefore, $5 \mathrm{lpm}$ (4.5\% total system volume perminute) were diverted from the PBR to the GEHC for gas exchange. This pumping rate provided the GEHC with an overdesign factor of 1.5 to ensure that carbon consumption in the PBR did not exceed the injection capacity and limit microalgae growth.

\subsection{GEHC Operation}

Diverting only a portion of the culture for $\mathrm{CO}_{2}$ injection resulted in a $\mathrm{pH}$ differential between the PBR and GEHC (Figure 8, top). This differential was greatest at times of the highest photosynthetic activity, which correlated with the highest PAR and highest gas injection rate during the day when most inorganic carbon was consumed (Figure 8, bottom). The control system could maintain the $\mathrm{pH}$ near the setpoint (7.60), indicating that the mass transfer rate of $\mathrm{CO}_{2}$ in the GEHC was not exceeded by the rate of carbon removal in the PBR. Thus the control system could monitor and deliver the amounts of $\mathrm{CO}_{2}$ demanded by the microalgae. Furthermore, this system reduced $\mathrm{CO}_{2}$ losses as compared to "on-off" systems that produce hysteresis and potentially large variations from the de- sired $\mathrm{pH}$ setpoint $[22,32]$. Further improvements in process control may be realized using predictive models to control pumping rates. Rubio et al. [31] developed a predictive model capable of estimating carbon depletion in tubular bioreactors based on $\mathrm{pH}$ differential, which could be adapted for the OMEGA system by comparing $\mathrm{pH}$ in the PBRs versus the GEHC. Further research is needed to determine how such pumping controls could improve

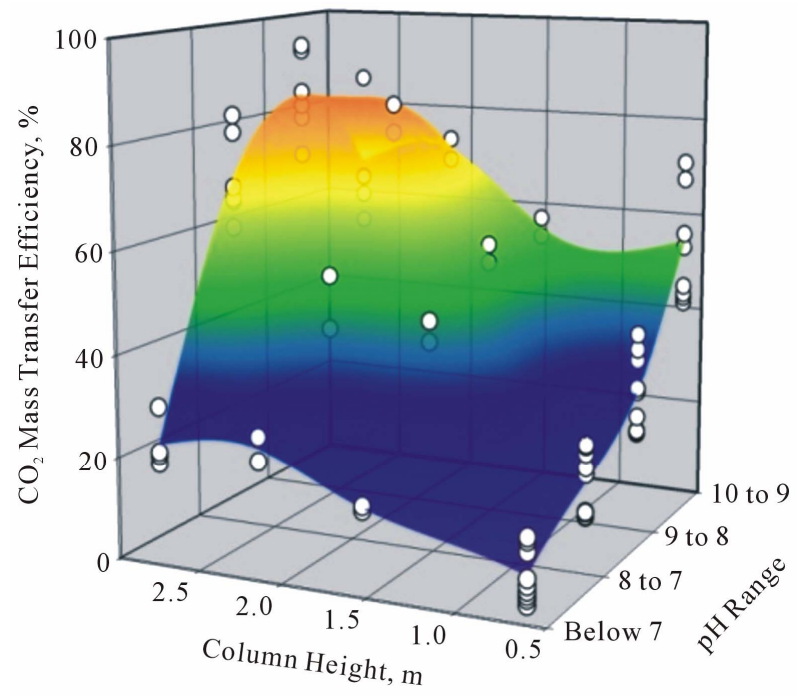

Figure 7. Efficiency of $\mathrm{CO}_{2}$ mass transfer in the GEHC relative to the height of the column and the $\mathrm{pH}$ of the solution. Data were obtained $(n=76)$ experimentally using tap water, pH adjusted $(>11.0)$ with $\mathrm{NaOH}$. For practical reasons a maximum column height of 1.8 meters was used.

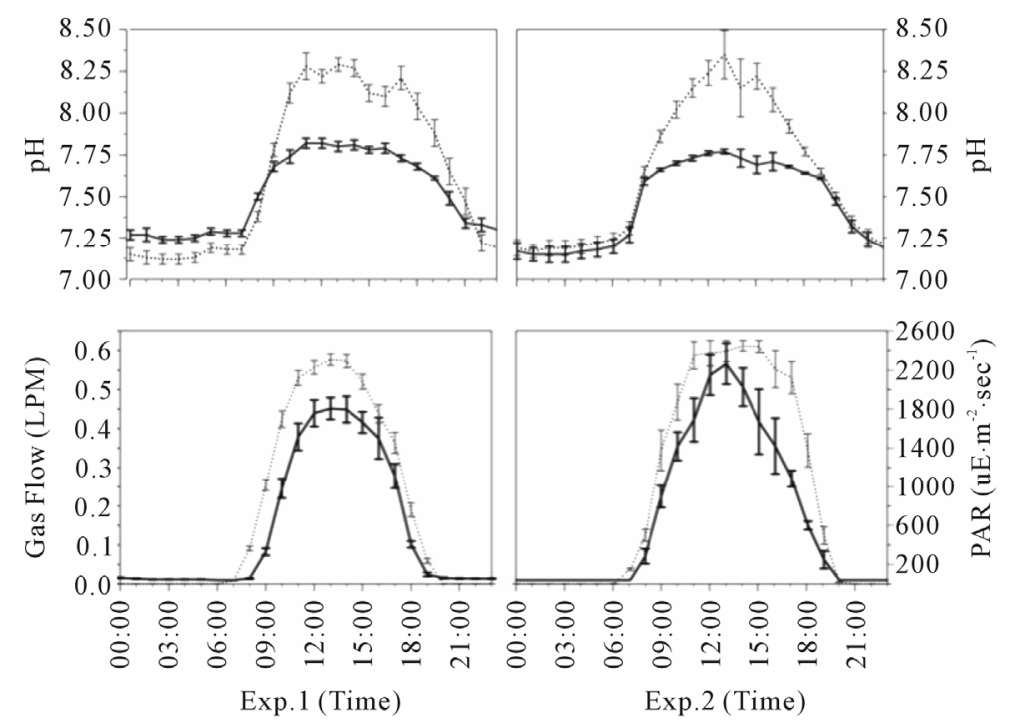

Figure 8. The mean hourly ( \pm SE) pH, gas flow, and PAR recorded during Experiment 1 (left) and Experiment 2 (right). Top: pH values measured inside the GEHC (solid line) compared to $\mathrm{pH}$ in the PBR (dotted line). The differential between the GEHC and PBRs increases during the day due to carbon assimilation for photosynthesis. The rate of $\mathrm{CO}_{2}$ injection was controlled to maintain the GEHC pH setpoint during the day. The slow decrease in $\mathrm{pH}$ at night is attributed to respiration. Bottom: Gas flow rates (solid lines) indicating $\mathrm{CO}_{2}$ demand correlated with PAR (dotted lines), and inferred rates of photosynthesis. The $\mathrm{pH}$ of the GEHC and PBRs equalize at night due to respiration. 
energy efficiency and biomass productivity.

The details of harvesting intervals, biomass production, and carbon utilization for both Experiments 1 and 2 are given in Table 1. Harvesting occurred every 0.83 to 2.79 days, triggered by the depletion of $\mathrm{NH}_{3}-\mathrm{N}$ (see below). It was noted that microalgae accumulated in the settling chamber at the bottom of the GEHC hence the biomass in the GEHC was higher than in the PBRs by a factor of $2.0 \pm 0.1(n=7)$ in Experiment 1 and $1.4 \pm 0.1(n=7)$ in Experiment 2. These calculated concentration factors were based on the total volume of the GEHC however, and therefore do not represent the concentrations at the bottom of the settling chamber.

Harvesting efficiency in the GEHC could be improved by adding coagulants or by integrating an electrocoagulation (EC) system, which produces coagulants in situ $[41,42]$. The EC system is well suited for OMEGA because it has no moving parts and is easily automated [42, 43]. Furthermore, by adding a small amount of seawater to the culture isolated in the GEHC, which would increase its ionic strength, would lower the power required for EC and electrolysis would produce electrolytic chlorine, which could contribute to disinfecting the residual water before release into the environment $[43,44]$. Additional research is needed to assess the EC harvesting process for the OMEGA system.

\subsection{Carbon Utilization and Biomass Production}

The totalized volume of simulated flue gas $\left(8.5 \% \mathrm{CO}_{2} /\right.$ 91.5\% air V/V) injected into the GEHC and the biomass produced during Experiments 1 and 2 are shown in Figure 9. The changes in gas utilization, which appear as a "staircase" in the plot, reflect the day/night cycles and the on-demand input of $\mathrm{CO}_{2}$. The curve slopes upward during light periods due to increased gas flow required to satisfy the carbon demand for photosynthesis by the microalgae. The curve plateaus during dark periods when there is no $\mathrm{CO}_{2}$ demand. The biomass produced relative

Table 1. Harvesting frequency, biomass yields and mass of carbon injected into the GEHC used to calculate carbon conversion efficiency and areal biomass productivity during Experiment 1 and 2.

\begin{tabular}{|c|c|c|c|c|c|c|}
\hline \multicolumn{7}{|c|}{ Experiment 1} \\
\hline $\begin{array}{l}\text { Elapsed Time, } \\
\text { Days }\end{array}$ & $\begin{array}{c}\text { Days between } \\
\text { Harvest }\end{array}$ & $\begin{array}{c}\text { Biomass } \\
\text { Produced, } \mathrm{g}\end{array}$ & $\begin{array}{c}\text { Carbon } \\
\text { Required, } \mathrm{g}\end{array}$ & Carbon Injected, $\mathrm{g}$ & $\begin{array}{c}\text { Carbon Conversion } \\
\text { Efficiency, } \%\end{array}$ & $\begin{array}{c}\text { Biomass } \\
\text { Productivity, } \\
\mathrm{g} \cdot \mathrm{m}^{-2} \cdot \text { day }^{-1}\end{array}$ \\
\hline 1.85 & 1.85 & 5.2 & 2.6 & 5.8 & 45.0 & 4.0 \\
\hline 2.83 & 0.98 & 8.4 & 4.2 & 8.2 & 51.3 & 12.3 \\
\hline 3.66 & 0.83 & 2.6 & 1.3 & 4.1 & 31.6 & 4.5 \\
\hline 4.79 & 1.13 & 13.4 & 6.7 & 13.1 & 51.1 & 17.0 \\
\hline 6.73 & 1.94 & 23.1 & 11.5 & 18.0 & 64.2 & 17.1 \\
\hline 8.75 & 2.02 & 15.3 & 7.7 & 12.9 & 59.4 & 10.9 \\
\hline 9.68 & 0.93 & 11 & 5.5 & 10.1 & 54.5 & 17.0 \\
\hline 12.5 & 2.79 & 29.3 & 14.7 & 19.6 & 74.9 & 15.1 \\
\hline 13.5 & 1.06 & 15.2 & 7.6 & 14.5 & 52.5 & 20.6 \\
\hline \multicolumn{2}{|c|}{ Mean (SE) } & $13.7(4.6)$ & $6.9(1.4)$ & $11.8(1.8)$ & $53.8(4.0)$ & $13.2(1.9)$ \\
\hline \multicolumn{7}{|c|}{ Experiment 2} \\
\hline 0.92 & 0.92 & 6.1 & 3.0 & 7.1 & 42.7 & 9.5 \\
\hline 1.87 & 0.95 & 8.1 & 4.1 & 6.4 & 63.7 & 12.3 \\
\hline 2.89 & 1.02 & 15.4 & 7.7 & 11.4 & 67.7 & 21.7 \\
\hline 4.89 & 2.00 & 23.1 & 11.6 & 19.3 & 59.9 & 16.6 \\
\hline 5.88 & 0.99 & 12.3 & 6.2 & 11.0 & 56.2 & 17.8 \\
\hline 6.82 & 0.94 & 8.3 & 4.2 & 8.3 & 50.2 & 12.7 \\
\hline 8.61 & 1.79 & 21.0 & 10.5 & 13.0 & 80.9 & 16.8 \\
\hline \multicolumn{2}{|c|}{ Mean (SE) } & $13.5(2.5)$ & $6.8(1.3)$ & $10.9(1.7)$ & $60.2(4.7)$ & $15.3(1.6)$ \\
\hline
\end{tabular}



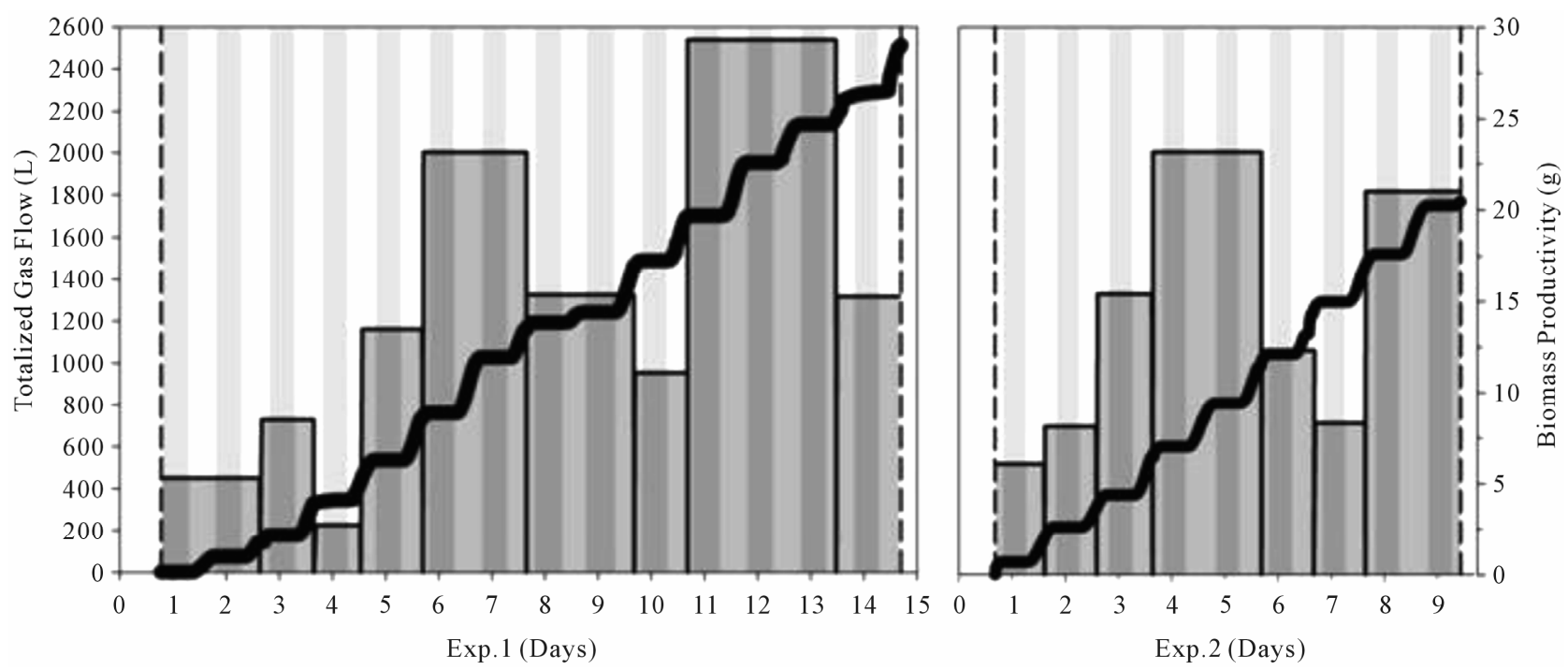

Figure 9. Microalgal $\mathrm{CO}_{2}$ utilization and productivity in Experiment 1 (left) and Experiment 2 (right) with the day/night cycle indicated by vertical stripes. Totalized gas flow $\left(8.5 \% \mathrm{CO}_{2} \mathrm{~V} / \mathrm{V}\right)$ (bold black line) and biomass production (histogram). The totalized gas flow has a "staircase" shape because $\mathrm{CO}_{2}$ was injected on demand; photosynthesis caused injection during the day (slope up), but not at night (plateaus). The histogram shows biomass production in the height of bars (right axis, g) and the time between harvesting in the width of the bars (bottom axis, days).

to the amount of $\mathrm{CO}_{2}$ injected was used to calculate the $\mathrm{CO}_{2}$ utilization efficiency (Table 1): For Experiment 1 the mean efficiency was $53.8 \% \pm 4.0 \%(\mathrm{n}=9)$ and for Experiment 2 it was $60.2 \% \pm 4.7 \%(n=7)$, with values from both experiments ranging from $31.6 \%$ to $80.9 \%$. These measured $\mathrm{CO}_{2}$ conversion efficiencies correspond well to the $\mathrm{CO}_{2}$ solubility values obtained in the titration experiment (see Section 3.3). Gas transfer in the OMEGA GEHC could be improved by using a taller column (greater contact time for rising bubbles), smaller bubbles (greater surface-to-volume ratio), or higher $\mathrm{CO}_{2}$ concentrations. The site restricted column height, available equipment determined the bubble size, and the $\mathrm{CO}_{2}$ concentration was chosen to simulate flue gas to determine if it would be adequate to support microalgae cultures in the prototype system.

The observed productivity, normalized to PBR surface area per day, averaged $13.2 \mathrm{~g} \pm 1.9(\mathrm{n}=9)$, in Experiment 1 and $15.3 \mathrm{~g} \pm 1.6(\mathrm{n}=7)$ in Experiment 2 (Table 1 $\&$ Figure 9 bars). In Experiment 1, sampling periods one and three had low biomass yields. The initially low yield, $4.0 \mathrm{~g} \cdot \mathrm{m}^{-2} \cdot \mathrm{day}^{-1}$, may have been due to a period of culture acclimation. The second low yield on the third harvest cycle $\left(4.5 \mathrm{~g} \cdot \mathrm{m}^{-2} \cdot \mathrm{day}^{-1}\right)$ was due to a short incubation period with minimal light exposure (Figure 9). Despite these limitations, the average observed areal productivities were within the range of values reported for open ponds $[10,45,46]$, although somewhat less than those reported for other PBR systems [5,47]. This disparity with other PBRs may be due to lower nutrient concentrations in the unsupplemented wastewater, the presence of grazers and/or pathogens, or to other limiting culture conditions (e.g., time of year or culture temperature). Long-term experiments are required to determine the limiting factors in the OMEGA system and its potential yields.

\subsection{OMEGA and Wastewater Treatment}

The OMEGA system used secondary wastewater effluent as a source of nutrients for microalgae cultures and the concentrations of ammonia $\left[\mathrm{NH}_{3}\right]$ and nitrate $\left[\mathrm{NO}_{3}^{-}\right]$ were monitored (Figure 10). The rapid utilization of $\mathrm{NH}_{3}$ required periodic replacement of spent culture medium with fresh wastewater. Between $16 \%$ and $34 \%$ of the total system volume was harvested from the GEHC and replenished to increase the concentration of $\left[\mathrm{NH}_{3}\right]$ (Figure 10; top). While $\left[\mathrm{NH}_{3}\right]$ followed a consistent pattern of utilization and replenishment, the corresponding $\left[\mathrm{NO}_{3}^{-}\right]$showed increases, decreases, or no change (Figure 10, middle). The increases in $\left[\mathrm{NO}_{3}^{-}\right]$were attributed to nitrification by ammonia-oxidizing bacteria which are known to be present in wastewater [48]. The decreases in $\left[\mathrm{NO}_{3}^{-}\right]$observed in Experiment 1 (days 5 - 8) and Experiment 2 (days $1-3$ and $4-6$ ) were attributed to the depletion of $\mathrm{NH}_{3}$ and the utilization of $\mathrm{NO}_{3}$ as the microalgae's secondary nitrogen source (Figure 10, middle). Changes in preferred nitrogen sources have been observed for other microalgae [49].

The calculated rates of ammonia removal varied, but were positive, whereas the rates of nitrate removal were both positive and negative; a "negative removal" rate means nitrate production (Figure 10, bottom). The $\mathrm{NH}_{3}$ 

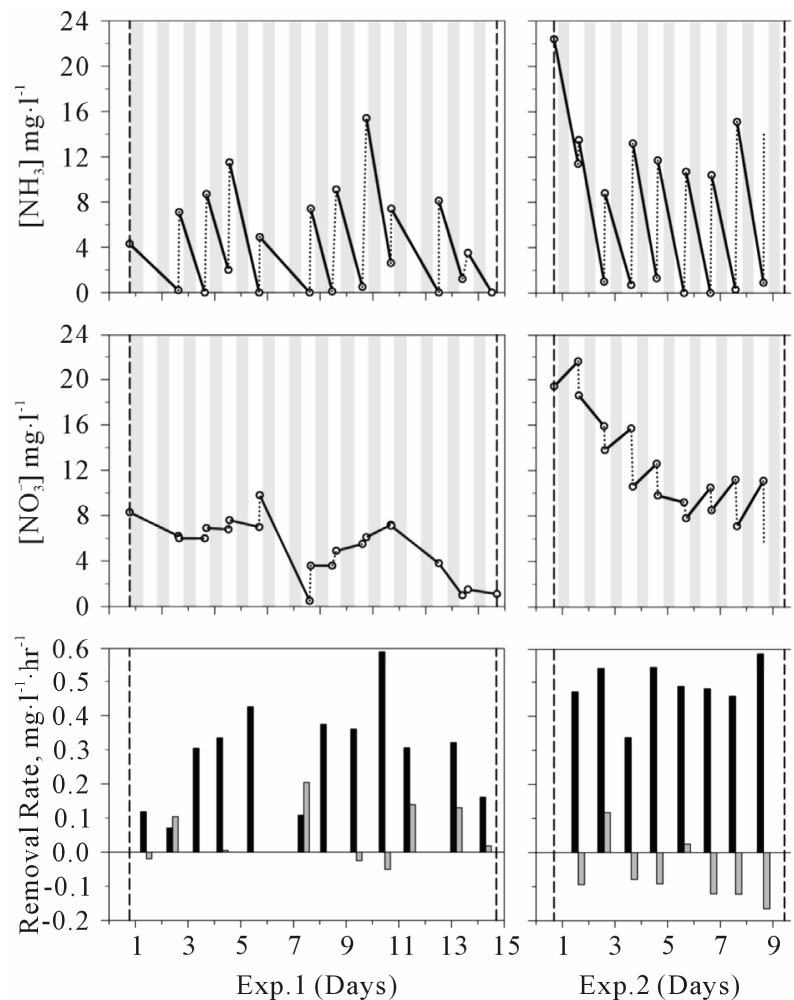

Figure 10. Time course for the addition and utilization of [ $\mathrm{NH}_{3}^{-} \mathrm{N}$ ] (top), [ $\mathrm{NO}_{3}^{-} \mathrm{N}$ ] (middle), and removal rates (bottom) for Experiment 1 (left) and Experiment 2 (right). As in Figure 9 the day/night cycle is represented by white/gray shading and each line segment (top/middle) shows changes in nutrient concentration from the time of wastewater addition to harvesting, corresponding to "biomass production" bars in Figure 9. Removal rates (bottom) are shown as positive when nutrients were depleted or negative when nutrient concentrations increased. The $\mathrm{NH}_{3}$ removal rates (black bars) were always positive, but $\mathrm{NO}_{3}^{-} \mathrm{N}$ removal rates (grey bar) were occasionally negative due to nitrification. The microalgae preferred $\mathrm{NH}_{3}^{-} \mathrm{N}$ as their nitrogen source and consume $\mathrm{NO}_{3}^{-} \mathrm{N}$ once the supply of $\mathrm{NH}_{3}^{-} \mathrm{N}$ was exhausted.

removal rate averaged $0.29 \pm 0.04(\mathrm{n}=12)$ and $0.49 \pm$ $0.03(\mathrm{n}=11) \mathrm{mg} \cdot 1^{-1} \cdot \mathrm{hr}^{-1}$ for experiments 1 and 2 , respectively. In contrast, $\mathrm{NO}_{3}^{-}$removal rates were predominantly positive during experiment 1 but predominantly negative in Experiment 2. In both experiments the actual nitrate concentrations represented the combination of production and utilization at each sampling point. A more effective utilization of total nitrogen may be achieved with longer retention times.

These results indicate that microalgae growing in a prototype OMEGA system can contribute to biological nutrient removal in wastewater treatment. It is well established that microalgae in ponds and other PBR designs can effectively remove nutrients from wastewater [50-53]. It has also been demonstrated that microalgae can remove heavy metals $[53,54]$ and organic contaminants, including surfactants, phenols, and hydrocarbons [53,55-57]. Research reported elsewhere indicates that the OMEGA system can also contribute to the removal of pharmaceuticals and personal care products as well as compounds of emerging concern [58].

Combining microalgae cultivation with wastewater treatment can improve water quality and provide biomass for biofuels or other products, but it remains to be demonstrated that the economics and EROI of the combined systems support its development $[6,9,14]$.

\section{Conclusions}

OMEGA has the potential of co-locating microalgae cultivation with two major waste-streams from coastal cities: wastewater and $\mathrm{CO}_{2}$. By situating OMEGA systems in the vicinity of offshore wastewater outfalls and $\mathrm{CO}_{2}$ sources, such as near-shore power plants, OMEGA can transform these waste streams into resources that produce biofuels and treat wastewater without competing with agriculture for water, fertilizer, or land [12]. The experiments presented here explored the technical feasibility of OMEGA, using a 110-liter prototype system that was built and tested over a 23-day period. Microalgae in secondary-treated wastewater circulated through PBRs floating in seawater tanks and through a gas exchange and harvesting column, while a custom I\&C system monitored and controlled critical culture parameters. Analyses indicated that the system was supersaturated with dissolved oxygen during the day due to photosynthesis, but at the highest light levels there was only slight photoinhibition. The system rapidly used the $\mathrm{NH}_{3}^{-} \mathrm{N}$ in wastewater and had a $\mathrm{CO}_{2}$ conversion efficiency of $>50 \%$; better than the $10 \%-20 \%$ conversions in other systems $[21,38]$. The areal productivity of the system averaged $14.1 \mathrm{~g} \cdot \mathrm{m}^{-2} \cdot$ day $^{-1}$ overall with peaks above $20 \mathrm{~g} \cdot \mathrm{m}^{-2} \cdot$ day $^{-1}$, values consistent with reported US average microalgae productivity of $13.2 \mathrm{~g} \cdot \mathrm{m}^{-2} \cdot \mathrm{day}^{-1}$ [59]. The microalgae consistently removed $>90 \%$ of the $\mathrm{NH}_{3}^{-} \mathrm{N}$ from the secondary-treated municipal wastewater tested. This result, combined with observations that the OMEGA system can remove other wastewater contaminants [58], suggests that a scaled-up system could provide effective wastewater treatment services.

Many open questions remain with regard to the feasibility of large-scale OMEGA systems. The small-scale prototype OMEGA system was intended for experimentation and was not designed for energy efficiency or economical scale up. For large-scale OMEGA deployment dense configurations of PBRs, improved hydrodynamics, optimized pumping and mixing, and more sophisticated process control algorithms will be needed to increase yields, improve EROI, and lower operating costs. In addition to the EROI and economics, questions about the 
impact of biofouling, concerns about engineering systems that can cope with marine environments, and environmental issues around both environmental impact and environmental regulations will need to be answered. It remains to be seen if the need for sustainable biofuels will drive the innovation necessary to address these questions to develop large-scale OMEGA systems.

\section{Acknowledgements}

The authors thank the OMEGA team members, in particular S. Ord, E. Austin, S. Fauth, A. Nazzal, A. Wong, S. Harmsen, S. Eckhart, S. Martin, P. Buckwalter, J. VanGelder, R. Tanakit, K. Acierto, Z. Hall, B. Smith, S. Toy-Choutka, C. Young, S. Zimmerman, S. Marwood, K. Long, S. Jayaprakash, M. Primack, W. Chen, J. Kaehms, and C. Dye, as well as D. Jessup and M. Miller at the California Department of Fish and Game, M. Ortega at Santa Cruz Wastewater Treatment Facility, S. Lamerdin and J. Douglas at Moss Landing Marine Laboratory, and G. Engel and J. Powell at the San Francisco Southeast Wastewater Water Treatment Plant. The OMEGA project was supported by NASA-ARMD and the California Energy Commission-PIER.

\section{REFERENCES}

[1] T. Mata, A. Martins and N. Caetano, "Microalgae for Biodiesel Production and Other Applications: A Review," Renewable and Sustainable Energy Reviews, Vol. 14, No. 1, 2010, pp. 217-232. doi:10.1016/j.rser.2009.07.020

[2] G. C. Dismukes, et al., "Aquatic Phototrophs: Efficient Alternatives to Land-Based Crops for Biofuels," Current Opinion in Biotechnology, Vol. 19, No. 3, 2008, pp. 235240. doi:10.1016/j.copbio.2008.05.007

[3] Y. Chisti, "Biodiesel from Microalgae," Biotechnology Advances, Vol. 25, No. 3, 2007, pp. 294-306. doi:10.1016/j.biotechadv.2007.02.001

[4] M. Johnson and Z. Wen, "Production of Biodiesel Fuel from the Microalga Schizochytrium limacinum by Direct Transesterification of Algal Biomass," Energy \& Fuels, Vol. 23, No. 10, 2009, pp. 294-306. doi:10.1021/ef900704h

[5] Y. Shen, et al., "Microalgae Mass Production Methods," Transactions of the ASABE, Vol. 52, No. 4, 2009, pp. 12751287.

[6] C. M. Beal, et al., "Energy Return on Investment for Algal Biofuel Production Coupled with Wastewater Treatment," Water Environment Research, Vol. 89, No. 9, 2012, pp. 692-710. doi:10.2175/106143012X13378023685718

[7] A. Clarens, et al., "Environmental Life Cycle Comparison of Algae to Other Bioenergy Feedstocks," Environmental Science \& Technology, Vol. 44, No. 5, 2010, pp. 1813-1819. doi:10.1021/es902838n

[8] A. F. Clarens, et al., "Environmental Impacts of AlgaeDerived Biodiesel and Bioelectricity for Transportation,"
Environmental Science \& Technology, Vol. 45, No. 17, 2011, pp. 7554-7560. doi:10.1021/es200760n

[9] T. Lundquist, et al., "A Realistic Technology and Engineering Assessment of Algae Biofuel Production," Energy Biosciences Institute, Univeristy of California, Berkeley, 2010, p. 178.

[10] J. Park, R. Craggs and A. Shilton, "Wastewater Treatment High Rate Algal Ponds for Biofuel Production," Bioresource Technology, Vol. 102, No. 1, 2011, pp. 3542. doi:10.1016/j.biortech.2010.06.158

[11] M. O. P. Fortier and B. S. M. S. Sturm, "A Geographic Analysis of the Feasibility of Collocating Algal Biomass Production with Wastewater Treatment Plants," Environmental Science \& Technology, Vol. 46, No. 20, 2012, pp. 11426-11434. doi:10.1021/es302127f

[12] J. Trent, et al., "Research Spotlight: The Future of Biofuels: Is It in the Bag?" Biofuels, Vol. 3, No. 5, 2012, pp. 521-524. doi: $10.4155 / \mathrm{bfs} .12 .53$

[13] J. Trent, "Wind Sea Algae," International Workshop on Offshore Algae Cultivation, Lolland, 20-22 April 2009.

[14] P. E. Wiley, J. E. Campbell and B. McKuin, "Production of Biodiesel and Biogas from Algae: A Review of Process Train Options," Water Environment Research, Vol. 83, No. 4, 2011, pp. 326-338. doi: $10.2175 / 106143010 X 12780288628615$

[15] L. Harris, et al., "Potential Impact of Biofouling on the Proposed Offshore Membrane Enclosures for Growing Algae (OMEGA)," Biofouling, 2012, under Review.

[16] J. H. Bailey-Brock, "Fouling Community Development on an Artificial Reef in Hawaiian Waters," Bulletin of $\mathrm{Ma}$ rine Science, Vol. 44, No. 2, 1989, pp. 580-591.

[17] K. A. Dafforn, T. M. Glasby and E. L. Johnston, "Comparing the Invasibility of Experimental 'Reefs' with Field Observations of Natural Reefs and Artificial Structures," PLoS One, Vol. 7, No. 5, 2012, Article ID: e38124. doi:10.1371/journal.pone.0038124

[18] W. Mulbry, P. Kangas and S. Kondrad, "Toward scrubbing the Bay: Nutrient Removal Using Small Algal Turf Scrubbers on Chesapeake Bay Tributaries," Ecological Engineering, Vol. 36, No. 4, 2010, pp. 536-541. doi:10.1016/j.ecoleng.2009.11.026

[19] M. C. Barnhart, "An Improved Gas-Stripping Column for Deoxygenating Water," Journal of the North American Benthological Society, Vol. 14, No. 2, 1995, pp. 347-350. doi:10.2307/1467786

[20] F. Kaštánek, et al., "In-Field Experimental Verification of Cultivation of Microalgae Chlorella sp. Using the Flue Gas from a Cogeneration Unit as a Source of Carbon Dioxide," Waste Management \& Research, Vol. 28, No. 11, 2010, pp. 961-966. doi:10.1177/0734242X10375866

[21] R. Putt, et al., "An Efficient System for Carbonation of High-Rate Algae Pond Water to Enhance $\mathrm{CO}_{2}$ Mass Transfer," Bioresource Technology, Vol. 102, No. 3, 2011, pp. 3240-3245. doi:10.1016/j.biortech.2010.11.029

[22] A. Carvalho, L. Meireles and F. Malcata, "Microalgal Reactors: A Review of Enclosed System Designs and Performances," Biotechnology Progress, Vol. 22, No. 6, 2006, pp. 1490-1506. 
[23] J. Doucha, F. Straka and K. Lívanský, "Utilization of Flue Gas for Cultivation of Microalgae Chlorella sp.) in an Outdoor Open Thin-Layer Photobioreactor," Journal of Applied Phycology, Vol. 17, No. 5, 2005, pp. 403-412. doi:10.1007/s10811-005-8701-7

[24] T. Sobczuk, et al., "Carbon Dioxide Uptake Efficiency by Outdoor Microalgal Cultures in Tubular Airlift Photobioreactors," Biotechnology and Bioengineering, Vol. 67, No. 4, 2000, pp. 465-475. doi:10.1002/(SICI)1097-0290(20000220)67:4<465::AIDBIT10>3.0.CO;2-9

[25] American Public Heath Association, "Standard Methods for the Examination of Water and Wastewater," Water Environment Federation, Alexandria, 1998.

[26] Z. S. Kolber, O. Prášil and P. G. Falkowski, "Measurements of Variable Chlorophyll Fluorescence Using Fast Repetition Rate Techniques: Defining Methodology and Experimental Protocols," Biochimica et Biophysica Acta (BBA)-Bioenergetics, Vol. 1367, No. 1, 1998, pp. 88-106. doi:10.1016/S0005-2728(98)00135-2

[27] A. Richmond, "Handbook of Microalgal Culture: Biotechnology and Applied Phycology," Wiley-Blackwell, Hoboken, 2004.

[28] H. Quiang, H. Guterman and A. Richmond, "Physiological Characteristics of Spirulina platensis Cultured at U1tra-High Cell Densities," Journal of Phycology, Vol. 32, No. 6, 1996, pp. 1066-1073. doi:10.1111/j.0022-3646.1996.01066.x

[29] J. Doucha and K. Livansky, "Productivity, $\mathrm{CO}_{2} / \mathrm{O}_{2} \mathrm{Ex}-$ change and Hydraulics in Outdoor Open High Density Microalgal (Chlorella sp.) Photobioreactors Operated in a Middle and Southern European Climate," Journal of Applied Phycology, Vol. 18, No. 6, 2006, pp. 811-826. doi:10.1007/s10811-006-9100-4

[30] P. Carlozzi and G. Torzillo, "Productivity of Spirulina in a Strongly Curved Outdoor Tubular Photobioreactor," Applied Microbiology and Biotechnology, Vol. 45, No. 1, 1996, pp. 18-23. doi:10.1007/s002530050642

[31] F. Rubio, et al., "Prediction of Dissolved Oxygen and Carbon Dioxide Concentration Profiles in Tubular Photobioreactors for Microalgal Culture," Biotechnology and Bioengineering, Vol. 62, No. 1, 1999, pp. 71-86. doi:10.1002/(SICI)1097-0290(19990105)62:1<71::AIDBIT9>3.0.CO;2-T

[32] M. Berenguel, et al., "Model Predictive Control of $\mathrm{pH}$ in Tubular Photobioreactors," Journal of Process Control, Vol. 14, No. 4, 2004, pp. 377-387. doi:10.1016/j.jprocont.2003.07.001

[33] B. S. Ferreira, et al., "Microporous Hollow Fibres for Carbon Dioxide Absorption: Mass Transfer Model Fitting and the Supplying of Carbon Dioxide to Microalgal Cultures," Journal of Chemical Technology \& Biotechnology, Vol. 71, No. 1, 1998, pp. 61-70.

doi:10.1002/(SICI)1097-4660(199801)71:1<61::AID-JC TB785>3.0.CO;2-R

[34] E. Grima, et al., "Gas-Liquid Transfer of Atmospheric $\mathrm{CO}_{2}$ in Microalgal Cultures," Journal of Chemical Technology and Biotechnology, Vol. 56, No. 4, 1993, pp. 329337. doi: $10.1002 /$ jctb. 280560402
[35] P. Talbot, et al., "Absorption of $\mathrm{CO}_{2}$ in Algal Mass Culture Systems: A Different Characterization Approach," Biotechnology and Bioengineering, Vol. 37, No. 9, 1991, pp. 834-842. doi:10.1002/bit.260370907

[36] C. M. Beal, et al., "The Energy Return on Investment for Algal Biocrude: Results for a Research Production Facility," BioEnergy Research, Vol. 5, No. 2, 2012, pp. 341362. doi:10.1007/s12155-011-9128-4

[37] C. M. Beal, et al., "Comprehensive Evaluation of Algal Biofuel Production: Experimental and Target Results," Energies, Vol. 5, No. 6, 2012, pp. 1943-1981. doi:10.3390/en5061943

[38] E. W. Becker, "Microalgae: Biotechnology and Microbiology," Cambridge University Press, Cambridge, 1994.

[39] A. Carvalho and F. Malcata, "Transfer of Carbon Dioxide within Cultures of Microalgae: Plain Bubbling versus Hollow-Fiber Modules," Biotechnology Progress, Vol. 17, No. 2, 2001, pp. 265-272. doi:10.1021/bp000157v

[40] A. Kumar, et al., "A Hollow Fiber Membrane PhotoBioreactor for $\mathrm{CO}_{2}$ Sequestration from Combustion Gas Coupled with Wastewater Treatment: A Process Engineering Approach," Journal of Chemical Technology \& Biotechnology, Vol. 85, No. 3, 2010, pp. 387-394. doi: $10.1002 /$ jetb. 2332

[41] S. Gao, et al., "Electro-Coagulation-Flotation Process for Algae Removal," Journal of Hazardous Materials, Vol. 177, No. 1-3, 2009, pp. 336-343. doi:10.1016/j.jhazmat.2009.12.037

[42] P. Holt, G. Barton and C. Mitchell, "The Future for Electrocoagulation as a Localised Water Treatment Technology," Chemosphere, Vol. 59, No. 3, 2005, pp. 355-367. doi:10.1016/j.chemosphere.2004.10.023

[43] G. Mouedhen, et al., "Behavior of Aluminum Electrodes in Electrocoagulation Process," Journal of Hazardous Materials, Vol. 150, No. 1, 2008, pp. 124-135. doi:10.1016/j.jhazmat.2007.04.090

[44] G. Azarian, et al., "Algae Removal by Electro-Coagulation Process, Application for Treatment of the Effluent from an Industrial Wastewater Treatment Plant," Iranian Journal of Public Health, Vol. 36, No. 4, 2007, pp. 5764.

[45] P. Chen, et al., "Review of the Biological and Engineering Aspects of Algae to Fuels Approach," International Journal of Agricultural and Biological Engineering, Vol. 2, No. 4, 2009, pp. 1-30.

[46] O. Pulz, "Photobioreactors: Production Systems for Phototrophic Microorganisms," Applied Microbiology and Biotechnology, Vol. 57, No. 3, 2001, pp. 287-293. doi:10.1007/s002530100702

[47] Y. Lee, "Microalgal Mass Culture Systems and Methods: Their Limitation and Potential," Journal of Applied Phycology, Vol. 13, No. 4, 2001, pp. 307-315. doi:10.1023/A:1017560006941

[48] L. Downing, et al., "Nitrogen Removal from Wastewater Using a Hybrid Membrane-Biofilm Process: Pilot-Scale Studies," Water Environment Research, Vol. 82, No. 3, 2010, pp. 195-201. doi:10.2175/106143009X426103

[49] Y. S. Yun, et al., "Carbon Dioxide Fixation by Algal 
Cultivation Using Wastewater Nutrients," Journal of Chemical Technology and Biotechnology, Vol. 69, No. 4, 1997, pp. 451-455. doi:10.1002/(SICI)1097-4660(199708)69:4<451::AID-JC TB733>3.0.CO;2-M

[50] D. Aitken and B. Antizar-Ladislao, "Achieving a Green Solution: Limitations and Focus Points for Sustainable Algal Fuels," Energies, Vol. 5, No. 5, 2012, pp. 16131647. doi:10.3390/en5051613

[51] L. Christenson and R. Sims, "Production and Harvesting of Microalgae for Wastewater Treatment, Biofuels, and Bioproducts," Biotechnology Advances, Vol. 29, No. 6, 2011, pp. 686-702. doi:10.1016/j.biotechadv.2011.05.015

[52] L. B. Christenson and R. C. Sims, "Rotating Algal Biofilm Reactor and Spool Harvester for Wastewater Treatment with Biofuels by Products," Biotechnology and Bioengineering, Vol. 109, No. 7, 2012, pp. 1674-1884. doi:10.1002/bit.24451

[53] L. E. de-Bashan and Y. Bashan, "Immobilized Microalgae for Removing Pollutants: Review of Practical Aspects," Bioresource Technology, Vol. 101, No. 6, 2010, pp. 1611-1627. doi:10.1016/j.biortech.2009.09.043

[54] H. V. Perales-Vela, J. M. Pena-Castro and R. O. Canizares-
Villanueva, "Heavy Metal Detoxification in Eukaryotic Microalgae," Chemosphere, Vol. 64, No. 1, 2006, pp. 1-10. doi:10.1016/j.chemosphere.2005.11.024

[55] Q. Gao, Y. Wong and N. Tam, "Removal and Biodegradation of Nonylphenol by Different Chlorella Species," Marine Pollution Bulletin, Vol. 63, No. 5, 2011, pp. 445451. doi:10.1016/j.marpolbul.2011.03.030

[56] Y. Ghasemi, S. Rasoul-Amini and E. Fotooh-Abadi, "The Biotransformation, Biodegradation and Bioremediation of Organic Compounds by Microalgae," Journal of Phycology, Vol. 47, No. 5, 2011, pp. 969-980. doi:10.1111/j.1529-8817.2011.01051.x

[57] R. Munoz and B. Guieysse, "Algal-Bacterial Processes for the Treatment of Hazardous Contaminants: A Review," Water Research, Vol. 40, No. 15, 2006, pp. 2799 2815. doi:10.1016/j.watres.2006.06.011

[58] E. P. Kolodziej, et al., "Muncipal Wastewater Treatment Using an OMEGA Photobioreactor," Water Research, under Review.

[59] US DOE, "National Algal Biofuels Technology Roadmap," US Department of Energy, Office of Energy Efficiency and Renewable Energy, Biomass Program, 2010. http://biomass.energy.gov 


\section{Nomenclature}

$\mathrm{Q}_{\text {Gas }}=$ Gas flow rate, $1 \mathrm{pm}$

$\mathrm{P}_{\text {Algae }}=$ Microalgal productivity, $\mathrm{g} \cdot \mathrm{m}^{-2} \cdot \mathrm{day}^{-1}$

$\mathrm{f}_{\text {Carbon }}=$ Fraction carbon in biomass

$\mathrm{A}_{\mathrm{PBR}}=$ Area of the PBR tubes, $\mathrm{m}^{2}$

$\mathrm{R}=$ Ideal gas constant, $0.08206 \mathrm{~L}$-atm mol- $\mathrm{K}^{-1}$

$\mathrm{T}=$ Temperature, $\mathrm{K}$

$\mathrm{f}_{\mathrm{Abs}}=$ Fraction $\mathrm{CO}_{2}$ absorbed

$D_{\text {Solar }}=$ Length of solar day, hours

$\mathrm{M}_{\mathrm{Car}}=$ Molar mass of carbon, $\mathrm{g} \cdot \mathrm{mol}^{-1}$

$\mathrm{pCO}_{2}=\mathrm{CO}_{2}$ partial pressure, atm

$\mathrm{M}_{\mathrm{CO}_{2}}=$ Moles of $\mathrm{CO}_{2}$

$\mathrm{t}=$ Time, minutes

$\mathrm{CO}_{2_{\mathrm{Eff}}}=\mathrm{CO}_{2}$ mass transfer efficiency, \%

$\mathrm{M}_{\mathrm{NaOH}}=$ Moles of $\mathrm{NaOH}$

$\mathrm{K}_{\mathrm{L}} \mathrm{a}=$ Overall volumetric mass transfer coefficient, $\min ^{-1}$

$\mathrm{C}^{*}=$ Equilibrium $\left[\mathrm{CO}_{2}\right], \mathrm{mol} \cdot \mathrm{l}^{-1}$

$\mathrm{C}=\left[\mathrm{CO}_{2}\right], \mathrm{mol} \cdot \mathrm{l}^{-1}$
$\mathrm{PBR}_{\mathrm{Vol}}=$ Volume of PBR tubes, 1

$\mathrm{DTR}=$ Detention time ratio, unitless

$\mathrm{GEHC}_{\text {Xfer Rate }}=\mathrm{GEHC} \mathrm{CO}_{2}$ mass transfer rate, $\mathrm{mol} \cdot \mathrm{l}^{-1}$. $\min ^{-1}$

$\mathrm{C}_{\text {Uptake }}=$ Carbon uptake in the PBR, $\mathrm{mol} \cdot \mathrm{l}^{-1} \cdot \mathrm{min}^{-1}$

$\mathrm{A}_{\text {Growth }}=\mathrm{g}$, Total biomass produced

$\mathrm{TSS}_{\mathrm{GEHC}}=$ Total suspended solids content of culture harvested from GEHC, $\mathrm{mg} \cdot \mathrm{l}^{-1}$

$\mathrm{H}_{\mathrm{Vol}}=$ Volume of culture harvested from GEHC, 1

$\mathrm{TSS}_{\mathrm{PBR}}=$ Total suspended solids content of the culture in the PBR, $\mathrm{mg} \cdot \mathrm{l}^{-1}$

$\mathrm{I}_{\text {Mass }}=$ Initial mass of solids in the system, $\mathrm{g}$

$\mathrm{HCF}=$ Harvesting concentration factor, unitless

$\mathrm{D}_{\text {Harvest }}=$ Harvesting frequency, days

$\mathrm{CO}_{2 \text { Conv }} \quad \mathrm{CO}_{2}$ to biomass conversion efficiency, \%

$\mathrm{V}_{\text {Gas }}=$ Volume of gas injected into the GEHC between harvest periods 